\title{
Design for Additive Manufacturing: Benefits, Trends and Challenges
}

\author{
Benjamin Durakovic \\ International University of Sarajevo
}

\begin{tabular}{ll} 
Article Info & ABSTRACT \\
\cline { 1 - 2 } $\begin{array}{l}\text { Article history: } \\
\text { Received Nov 5, 2018 }\end{array}$ & $\begin{array}{l}\text { In past five years, there has been a rapid increase in the publication on } \\
\text { additive manufacturing (AM). Many technologies have been introduced in a } \\
\text { rapidly growing market. The designers are confronted with many challenges } \\
\text { in designing products for additive manufacturing. AM offers significant } \\
\text { Accepted Dec 10,2018 } \\
\text { advantages, but there are also many constraints for AM to be used in its full } \\
\text { potential. This paper explores trends, issues and challenges in design for AM, } \\
\text { including associated costs, design options, quality considerations. It has been } \\
\text { found that AM is in its infancy, there is insufficient understanding of the } \\
\text { process, method, strategies, tools applied in design for additive manufacturing } \\
\text { pesign for additive }\end{array}$ \\
process, while process quality and capabilities are continuously improving.
\end{tabular}

cost and complexity; Process

quality; DFAM method

\section{Corresponding Author:}

Benjamin Durakovic,

International University of Sarajevo,

Email: bdurakovic@ius.edu.ba

\section{Introduction}

\subsection{Design for conventional manufacturing}

Design for additive manufacturing has been used in literature frequently over past decades [1][2][3][4][5] but some authors tried to define it [6][7]. Therefore here is provided a brief overview of the design for additive manufacturing and its principles. Traditional design for manufacturing and assembly (DFMA), is about designing and optimizing product [8] [9] [10], together with manufacturing process improvement [11] [12] [13] with the aim of reducing time and cost [14] and increasing the quality [15] and performance of the product by considering design goals [16] and manufacturing constraint [17].

Design for Assembly (DFA) is concerned with reducing time and cost of a product assembly with the aim of making a product as easy as possible to assemble. This is usually achieved by minimizing number of assembly parts/components. As result, parts become more complex. Design for Manufacture (DFM), is concerned with reducing cost and complexity of manufactured parts with the aim of manufacturing product as easy as possible without reducing quality or performance of the part. This is usually achieved by minimizing manufacturing operations complexity and number of tight tolerances [18]. DFMA is a subset of Design for X [19], therefore it usually specifies the process [20] [21], feature [20] or activity [22]. Also, it explores relationship between design and manufacturing, its impact on the design process, and CAD improvement to support DFMA [20].

\subsection{Design for additive manufacturing}

All this mentioned for traditional DFM and DFA is valid for additive manufacturing (AM) as well. In practice, design knowledge, method, tools, and rules are different for design for additive manufacturing (DFAM). In DFAM process, different types of features must be created and different constraints must be applied that 
required specific design rules and tools [23][24][25][26][27][28]. Unlike traditional DFM, all additive manufacturing processes have different Bach size, reduces the need for certain activities such as assembling [29] and production time that cause different cost [30]. The biggest challenge of AM is the DFAM knowledge, understanding and application of DFAM method, tools, and rules. Therefore, the new knowledge has to be created to that includes new approaches, new materials and large complex spaces. To achieve this, the cognitive barriers and past experiences with traditional manufacturing techniques will have to be overcome [31].

AM has numerous advantages, but on the other hand, there are disadvantages as well. The advantages of this technology will continue to arise through continuous research efforts, which should be undertaken to eradicate and recognize the constraints which inhibit the use of this technology and eliminate constraints that inhibit the use of this technology. Design tools used for AM are more user-friendly and progressive simulation abilities are the key aspects which should be grasped. A notable benefit of AM is the possibility of mass customization, since it is devoid of the additional costs which arise due to mold making and tooling for a customized product. Therefore, mass production of several identical parts has the possibility of being as costeffective as the same number of different personalized goods [32]. The alteration among different designs is simple alongside with negligible added cost and with no need for special preparation. AM also has the possibility for mass production of complex geometries as well.

This paper aims to provide a review of DFAM recent developments, techniques in terms of the main methods employed, as well as its future development possibilities. The paper will also focus on other existing secondary and primary research to focus on the current research gaps, as well as to explore the challenges encountered in adopting this relatively "young" technology. Figure 1 shows the growing trend of publications over time from Scopus.

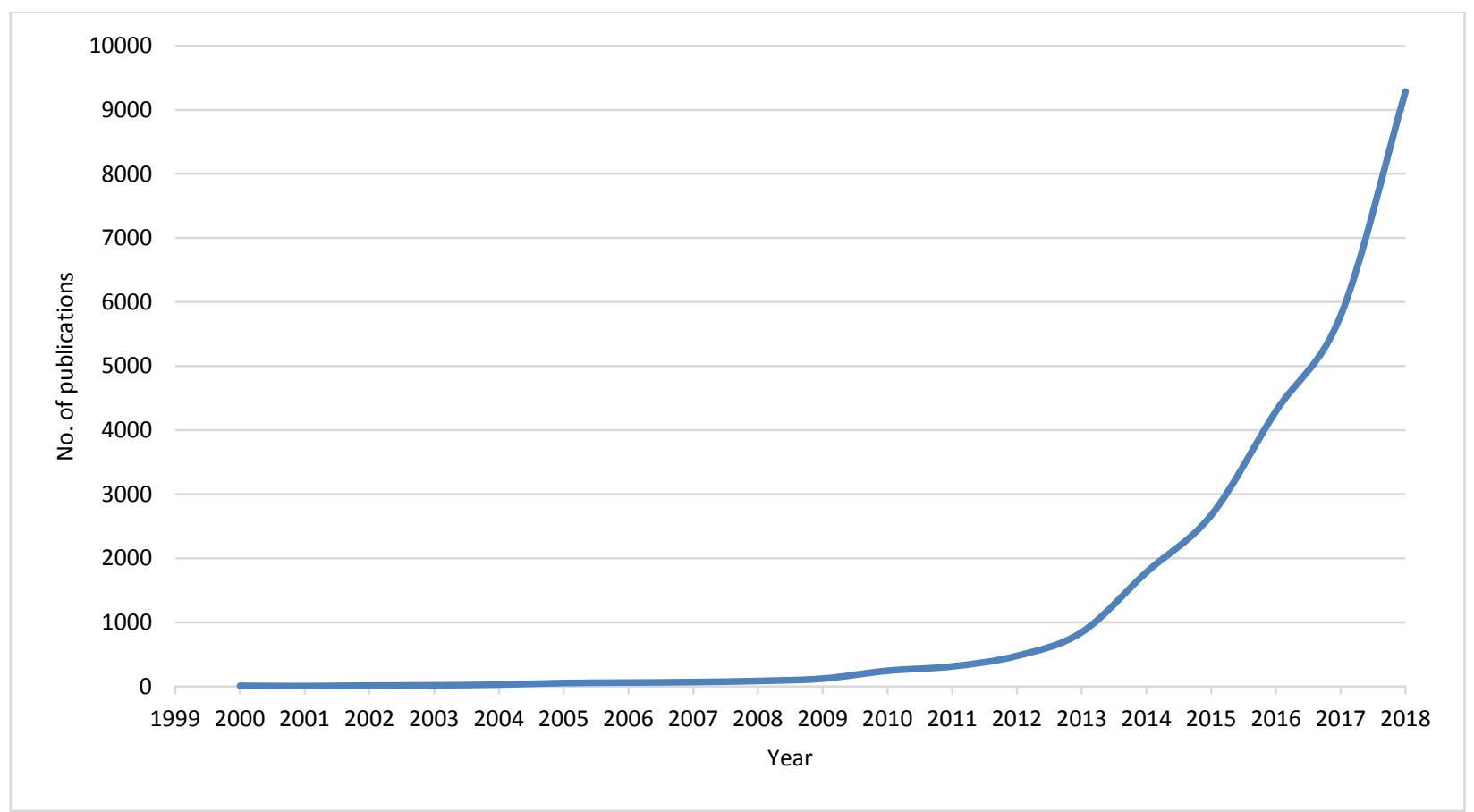

Figure 1. AM application in scientific research [33]

The figure above describes the application of AM in scientific research, and how the research interest for this technology grew over time. It is observed significant jump in publication since 2013.

\footnotetext{
${ }^{1}$ Data obtained from Scopus for search "additive manufacturing" OR "3D printing" in Title - abstact - Key words
} 


\section{Benefits of Additive Manufacturing}

AM technology is continuously improving with a capability of printing end user products from using diverse material including metallic and nonmetallic products [34]. It has many benefits over traditional manufacturing processes. The major advantages are shown in Table 1.

Table 1. Design opportunities and benefits of AM

\begin{tabular}{|c|c|c|}
\hline Advantages & Explanation & \\
\hline $\begin{array}{l}\text { Cost and geometry } \\
\text { complexity }\end{array}$ & $\begin{array}{l}\text { Cost is lower printing complex part instead of simple one } \\
\text { with the same size. } \\
\text { Possibility to produce near net shape, } \\
\text { Complex shape geometry with complex internal channels } \\
\text { that are not feasible with to make with conventional } \\
\text { manufacturing processes. }\end{array}$ & [35] [36] [37] \\
\hline $\begin{array}{l}\text { Functional } \\
\text { (Assembly may not be } \\
\text { required) }\end{array}$ & $\begin{array}{l}\text { In addition to single part manufacturing, there is possibility } \\
\text { to produce functional devices (such as hinges and bicycle } \\
\text { chains) if the technology permits the functional integration, } \\
\text { which recuces part count. }\end{array}$ & {$[38]$} \\
\hline Material complexity & $\begin{array}{l}\text { Possibility of manufacturing multiple materials in one } \\
\text { operation and complex composition of materials that } \\
\text { provides different properties at certain locations. }\end{array}$ & {$[39][40][41]$} \\
\hline Hierarchical complexity & $\begin{array}{l}\text { Possibility of design manufacturing various shapes of } \\
\text { internal structure (honeycomb, lattices or foams) to } \\
\text { increase strength to weight stiffness to weight ratio which } \\
\text { reduces material usage and cost. }\end{array}$ & {$[38][35][42]$} \\
\hline Low manufacturing skills & $\begin{array}{l}\text { No need for highly skilled professionals to make complex } \\
\text { parts and features, everyone who is able to create any 3D } \\
\text { model can create them with additive manufacturing. }\end{array}$ & {$[43]$} \\
\hline Reduced material waste & $\begin{array}{l}\text { There is very low waste of the material, only required } \\
\text { amount of the material is used. }\end{array}$ & [43] \\
\hline Part and material variety & $\begin{array}{l}\text { Possibility of manufacturing part similarity without } \\
\text { investment in extra tools, it is required to modify original } \\
\text { CAD file only. }\end{array}$ & [39] \\
\hline Design method & $\begin{array}{l}\text { Design method, tools and rules for AM products have been } \\
\text { reported in the literature which are tracing a new concept of } \\
\text { DFAM to get benefits from AM technologies }\end{array}$ & $\begin{array}{l}7] \\
{[44]}\end{array}$ \\
\hline Quality control & $\begin{array}{l}\text { Quality control method that includes sample size } \\
\text { requirements, settings and analysis procedures has been } \\
\text { discussed as well }\end{array}$ & {$[45]$} \\
\hline
\end{tabular}

Some of these most important advantages are discussed in detail in the following sub sections.

\subsection{Cost competitiveness}

Application of AM in industry is driven by costs and almost unlimited freedom of product design complexity. Compared to traditional subtractive manufacturing processes, AM has limited ability to use variety of materials and make part size, required prost processing because the parts are not close to final form, the part accuracy is low. Major advantages of AM are in lead time for one part that includes tooling and material procurement as well as capability to produce complex parts. Impact product design complexity on the production cost is shown in Figure 2, while the competitiveness of AM vs. traditional manufacturing is across various fields is shown in Figure 3. 


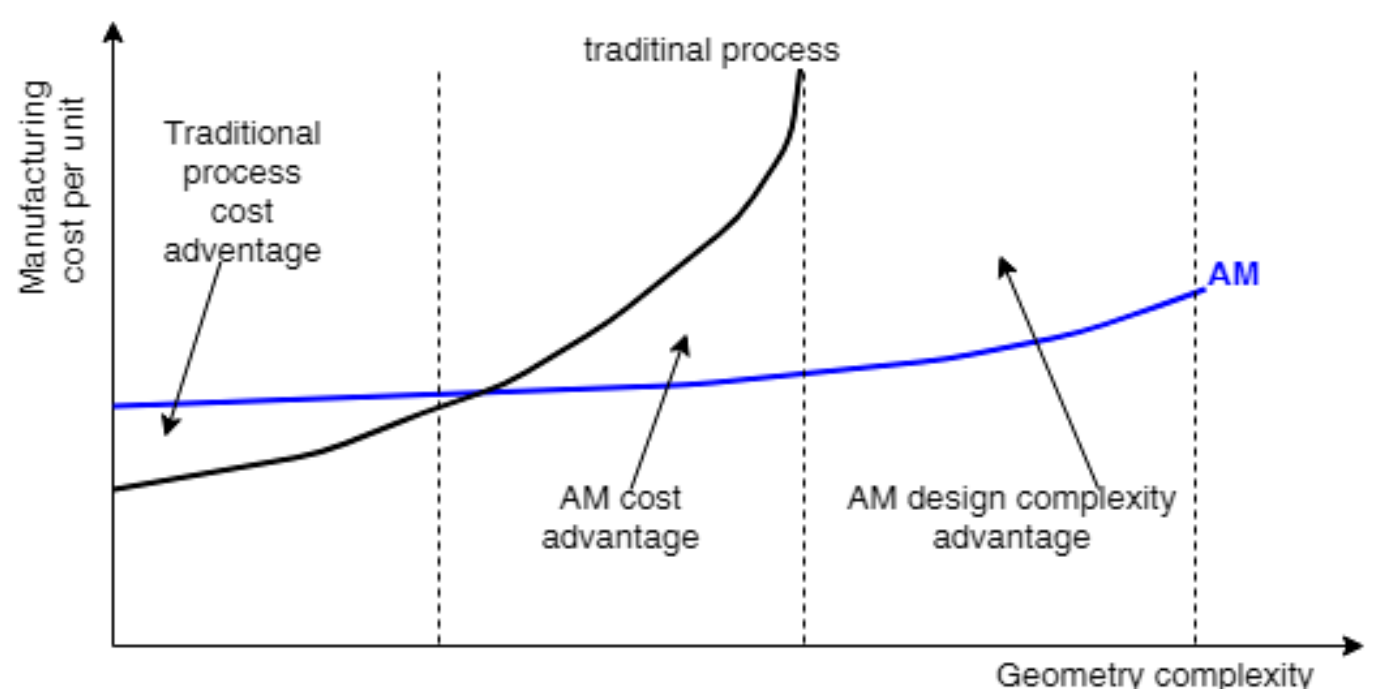

Figure 2. Relationship between cost and geometrical complexity in AM vs. traditional processes

Comparing manufacturing cost of a produced part, AM slightly increase with the geometry complexity while traditional subtractive manufacturing processes such as turning, milling etc. increase rapidly with part complexity.

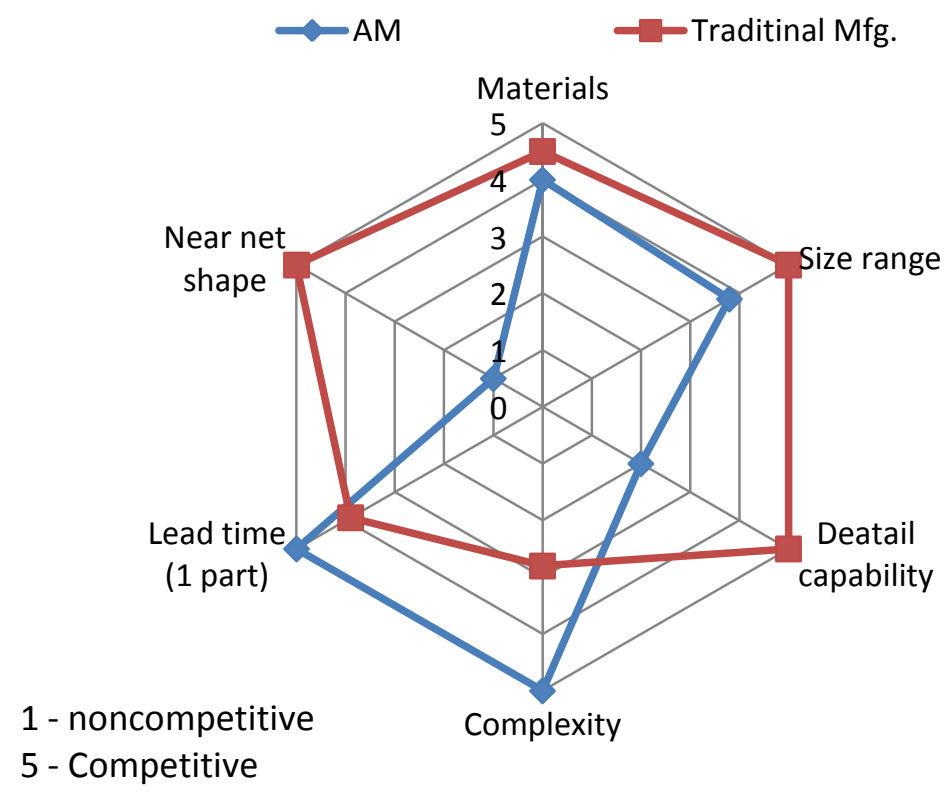

Figure 3. Additive vs. subtractive manufacturing competitiveness

To maintain AM manufacturing cost competitive, this relation worth for small series of complex geometry parts. Therefore, currently it has competitive application in processes such as cutting and investment casting. Design for additive manufacturing is about being able to build complex, cost effective and reliable parts. It considers also avoiding fixation on current design and locking into design for manufacturing (DFM) and design for assembly (DFA) principles that are major challenges in design for AM.

Supply chain differences between additive manufacturing and traditional manufacturing differs significantly. Significant amount of money, time and logistics management are required for functionality of traditional supply chain while the logistics in AM supply chain is reduced, which requires less money and time investment.

Forecasting of AM adoption rate vary significantly across industries, which is shown in Figure 4 [46] . 


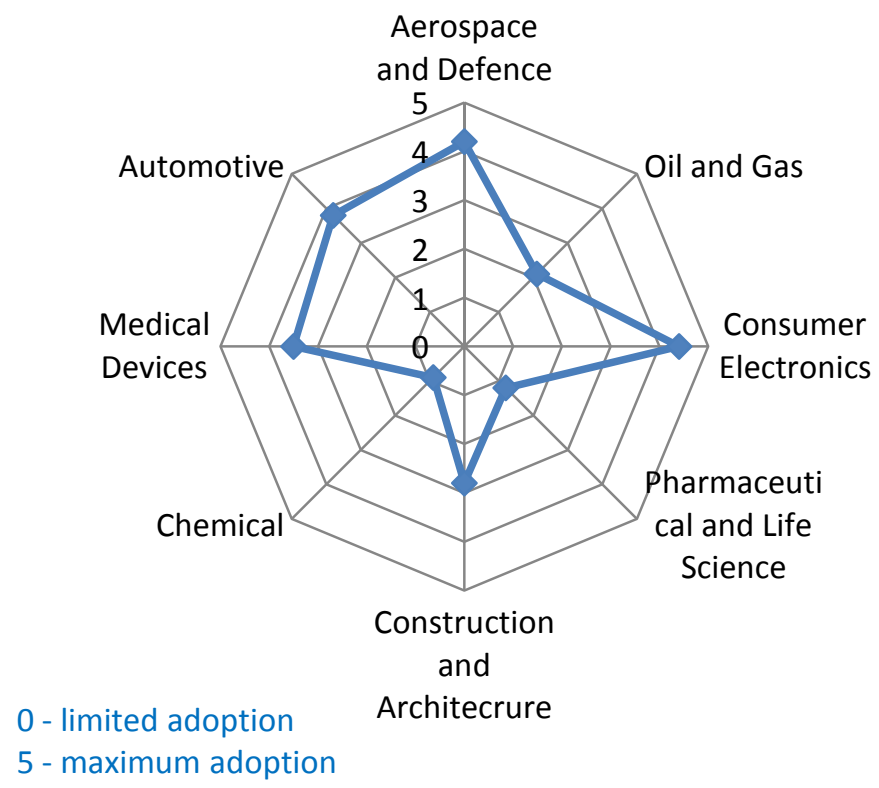

Figure 4. Adoption rate of AM across industries 2015-2025 forecasting

Referring to Figure 4, consumer electronics, aerospace and defense, automotive and medical devices are the most mature industries. In aerospace and defense industry AM is used to create lightweight parts such as engine parts and interior parts. In automotive industry AM is used to produce lightweight design and reduce the number of part and assembly groups by integrating multiple functions into a single part. In addition, it is used to produce tools and parts such as interior components, climate control and engine cooling parts. In industry of medical devices AM is used to produce medical and dental devices and implants, hearing aids, orthopedics and prosthetics in a cost-effective way.

\subsection{Geometry complexity - Design for improved function and design for topology optimization}

Very complex internal features can be created using AM to achieve the optimum performances of the product. These features cannot be created using traditional manufacturing processes. As it was shown in Figure 5, optimized fluid channel for conformal cooling. Integrated air ducts [47] and writing conduits [48] for robots were frequently studied as well.
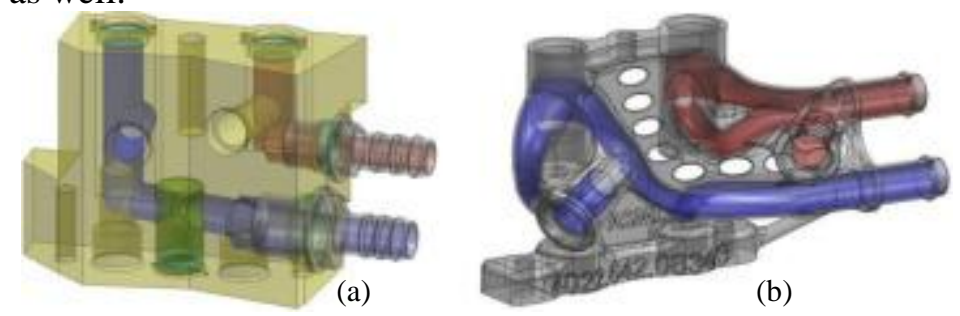

Figure 5. Design for improved function - Internal geometry freeform: (a) conventional cooling channel; (b) conformal cooling channel [49]

Heat transfer will be more effective if conformal cooling channels follow external geometry as it is shown in Figure 6. Traditional machining operation cannot achieve such shape of the channel. Conformal cooling improves efficiency and quality of injection molded parts [50]. This provides more uniform temperature distribution that reduces cycle time and costs, and improves quality [51].
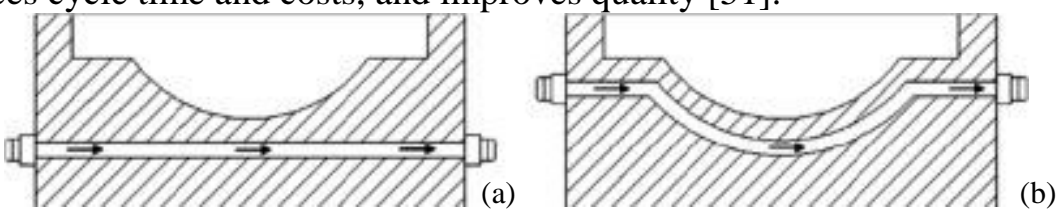

Figure 6. Design for improved function - Internal geometry freedom: (a) traditional channel; (b) conformal cooling channel [49] 
Possibility to manufacture geometry optimized parts based on numerical optimization. To achieve desired functionality, based on numerical simulation material is placed on those places where it is required. This is achieved with assumption that the part is made out of homogenous material. Part structure optimization is mainly used in automotive and aerospace industries [52]. This is extremely important in application where weight reduction is important design characteristic of product, which is most frequent case in aerospace industry [53], and improving biomedical implants [54].
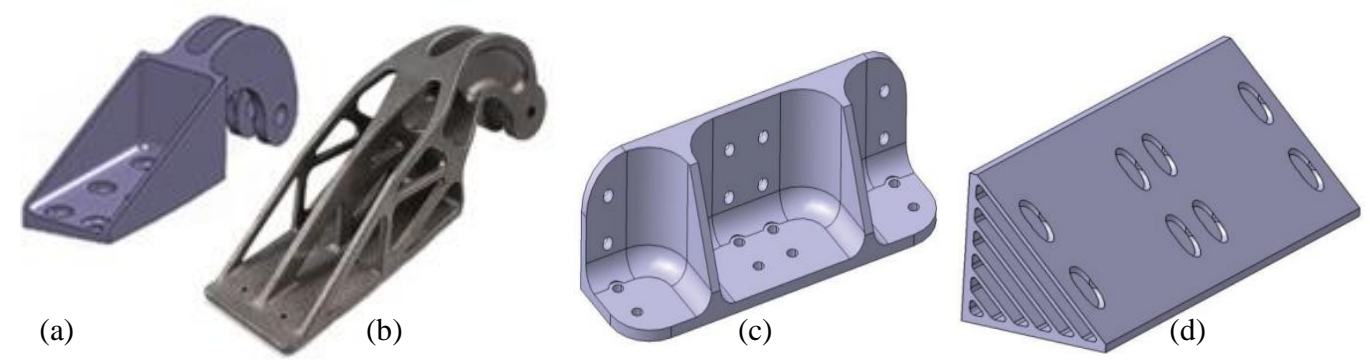

Figure 7. Design for topology optimization - brackets before and after geometry optimization for AM: (a) hinge bracket designed for cast steel [55]; (b) a new hinge bracket design for titanium [55]; (c) aluminum square bracket design for CNC machine; (d) a new design manufactured in Ti6Al4 on an EBM machine [56]

\subsection{Functional complexity - design for direct assembly manufacturing}

Direct assembly manufacturing is possible with AM. Moving parts such as bicycle chain, chain mails [57], armor [58], crank slider mechanisms [59], gears [60], hinge [30], and various types of joints [60], can be manufactured directly using AM. Figure 8 shows an example of additively manufactured assembly of the Italian aircraft P180 Avant II by Piaggio Aero Industries S.p.A [30]; and Figure 9 shows directly manufactured of assemblies joints and crank and slider mechanism [59].
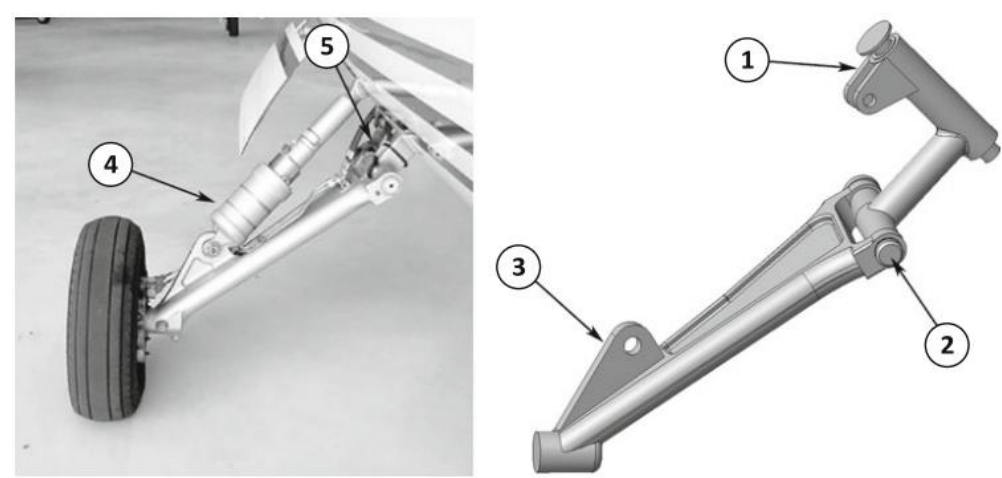

Figure 8. Main landing gear of the Italian aircraft P180 Avant II by Piaggio Aero Industries S.p.A [30]
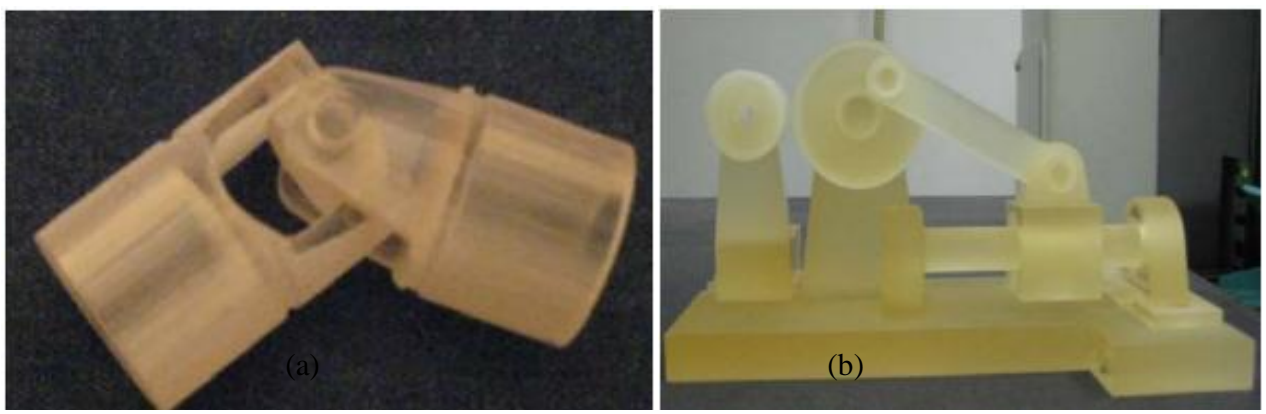

Figure 9. Direct production of assemblies: (a) joints; (b) crank and slider mechanism [59]

All these assemblies require clearance between particular parts, which can be achieved by using DFAM approach. 


\subsection{Material complexity}

Possibility of manufacturing multi-material parts and products in one operation and complex composition of materials that provides different properties at certain locations. To achieve this different feedstock or binder is used. Example of using multi-material additive manufacturing is seamless soccer boot [61], printed chair [62], motorcycle glove and multi-colored bike helmet [63], are shown in Figure 10.
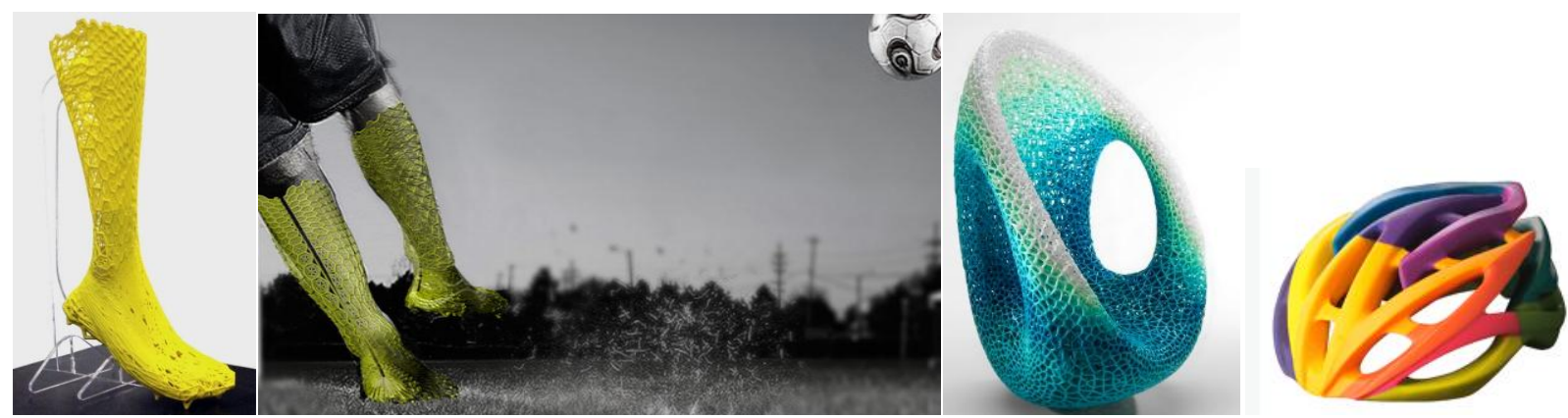

Figure 10. Multi-material products: (a) Seamless soccer boot [61] (b) Printing in "durotaxis chair" [62]; (b) multi-colored bike helmet [63]

Multimaterial AM was mentioned in literature with examples such as manufacturing of integrated electronics [64], art [65], compliant mechanism [66], or optimized structure topology [67].

\subsection{Part integration (Design for part integration)}

Instead of using complex assembly with lot of parts, AM allows designer to integrate assemblies in a single part. This eliminates assembly time, manufacturing time and reduces costs and inventory. Redesign for AM take in account design optimization of existing products in a way to reduce its weight or geometry optimization with maintaining or increasing product functionality and performances. An example of part integration is the nozzle used in GE Aviation for LEAP engines produced with metal AM. Part count is reduced from 18 to 1 ., and mass is reduced by $25 \%$. The durability of the part was increased by $500 \%$ an efficiency of the part [68]. The example is shown in Figure 11.

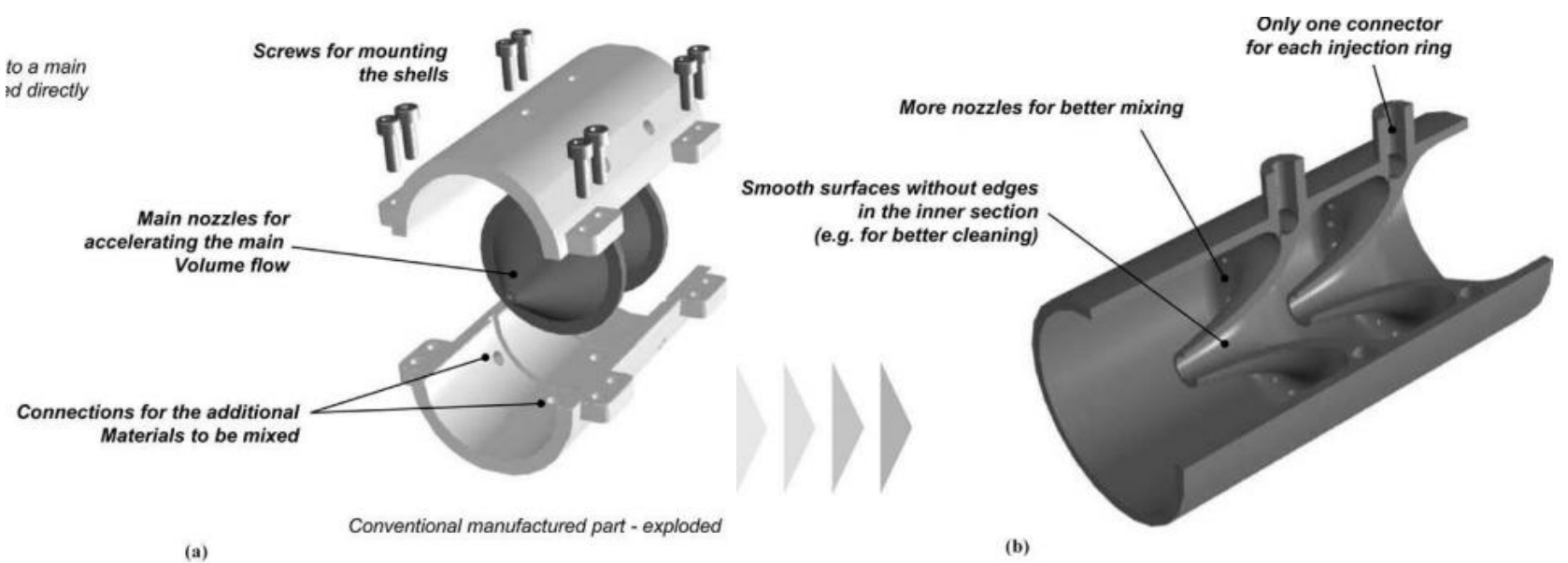

Figure 11. Part integration - assembly redesign to take the advantage of AM: (a) assembly - conventional manufactured parts; (b) the new consolidated design for AM - it is not longer an assembly [68]

More examples of part integration using AM were mentioned in literature with examples such as aircraft duct redesign reducing part count from 16 to 1 [4], robot gripper redesign by reducing part count from 9 to 1 [69], medical injector system packaging redesign reduced part count from 15 to 7 [70]. Much of this work show in this review is in conceptual stage, which requires a lot of research and development in this field to bring this technology to the market. 


\section{Design method for AM}

To get benefit from AM designers must learnt think "out of the box". Especially in cases of design of robust industrial solution, all strategies, tools, techniques and method must be adopted[71]. There are several design methods for additive manufacturing introduced in the literature but the most promising is the one that takes a functional surface approach and design part from the bottom up [26] [27] [72] [73]. Functional surface method requires very close link between design and Finite element analysis (FEA).

Functional surface method of design for additive manufacturing is explained in details in the literature, such as the one reported in [56]. Basically, it has four steps such as: (1) initial shape generation; (2) definition of parameters; (3) parametric optimization; (4) shape validation.

Initial shape generation - the goal is to get set of rough part shapes. The way a designer gets a new optimal shape can be very innovative. At this stage the designer may start defining the functional surfaces of the part. Functional surfaces are those interfaces between the considered part and its neighbors in assembly, or those surfaces that carry out the function of a fluid (gas or water, etc.). These surfaces must be linked based on the specific part exposure to mechanical or thermal load. At the end, main directions of the part are determined by the loads, therefore the shape of the part can be determined.
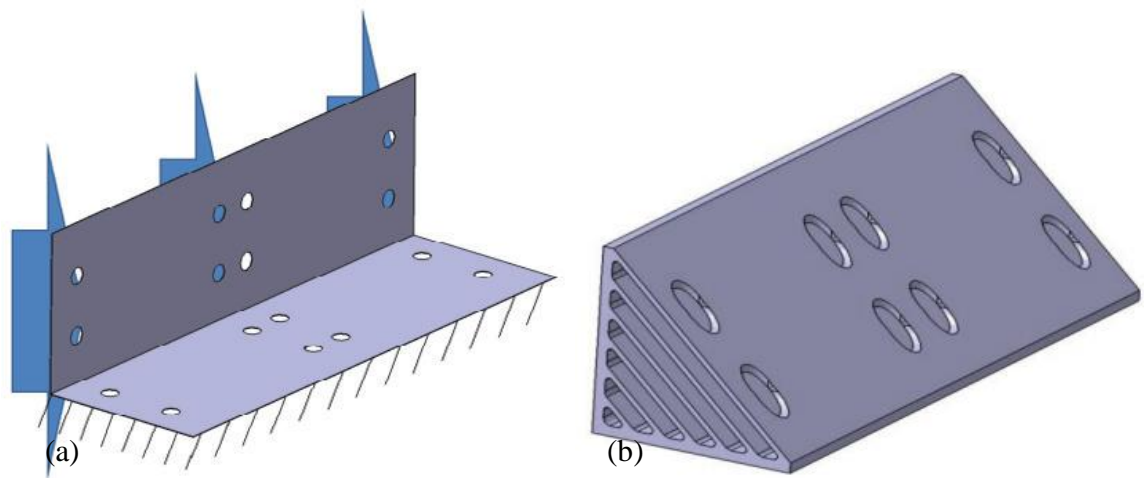

Figure 12. (a) Functional surfaces and mechanical load; (b) part sape [56]

Definition of parameters - to optimize the shape determined in the previous step, a relevant set of parameters have to be defined. The designer should be able to modify parameters associated with the part, it s geometry with respect to the part specifications and manufacturing constraints [56].

Parametric optimization - the goal is to reduce amount of raw material, energy consumption, manufacturing duration and associated cost. All of mentioned can be achieved by minimizing part volume. FEA is conducted for each iteration to verify part compliance with the specification.

Shape validation - the easiest way to validate manufacturability of the part is to use virtual manufacturing. The problem might be the lack of virtual validation tools at this state of the AM technology, thus directly AM can be still used for validation.

\section{Quality of produced part}

Parts produced using AM process face significant variation in quality, therefore it can not be used in high quality industrial applications. Major issues with quality are variability in: surface finish, geometry, mechanical properties, internal material defects [74]. Confidence that quality requirements of AM products are fulfilled has to be assured in order to be used in high quality application. Therefore, AM products must be fully certified for each step from the beginning to the end in supply chain that includes certification of the row material than all manufacturing step and finally produced part [75]. Major influencing factors that have a strong impact on AM process are machine/equipment, material, production, batch, part and data. A more detailed overview of the factors is shown in Figure 13 [76]. 


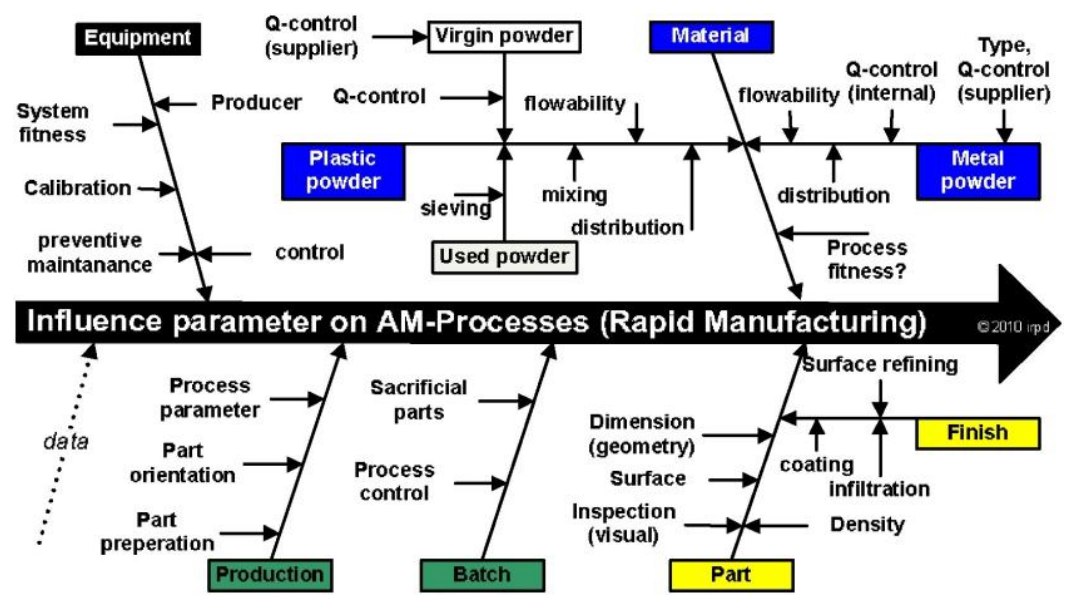

Figure 13. Factors that affect an AM process [77]

As it was shown from Figure 13, many major factors affect AM process. The number of factors that may affect the product quality is variable in the literature, depending of the AM process it can vary from 49 [78] to 130 [79].

\section{Conclusion}

Most of additive manufacturing studies are based on conceptual approaches, thus it can be said that it is still kind of in its infancy stage. DFAM is not defined well; there is insufficient understanding of the process method, strategies and when to undertake design for AM. Also many technologies are missing to support this process such as virtual additive manufacturing that takes in account thermal stress on the layer, so it will take time to gets its maturity stage. Process quality, capabilities and consistencies of AM are continuously improving. Currently existing standard are applying to AM but it is necessary to have AM-specific standards developed in the future. Even thought DFMA faces many challenges, still new products, design possibilities and manufacturing paradigms are born.

\section{References}

[1] D. Bourell, J. P. Kruth, M. Leu, G. Levy, D. Rosen, A. M. Beese and A. Clare, "Materials for additive manufacturing," CIRP Annals - Manufacturing Technology, 2017.

[2] W. E. Frazier, Metal additive manufacturing: A review, 2014.

[3] N. Guo and M. C. Leu, Additive manufacturing: Technology, applications and research needs, 2013.

[4] I. Gibson, D. W. Rosen and B. Stucker, Additive manufacturing technologies: Rapid prototyping to direct digital manufacturing, 2010.

[5] Ian Gibson · David Rosen Brent Stucker, Additive Manufacturing Technologies, 2015.

[6] J. P. Kruth, M. C. Leu and T. Nakagawa, "Progress in additive manufacturing and rapid prototyping," CIRP Annals Manufacturing Technology, 1998.

[7] D. W. Rosen, "Design for additive manufacturing: a method to explore unexplored regions of the design space," in 18th Annual Solid Freeform Fabrication Symposium, 2007.

[8] B. Durakovic and M. Torlak, "Experimental and numerical study of a PCM window model as a thermal energy storage unit," International Journal of Low-Carbon Technologies, vol. 12, no. 3, p. 272-280, 2017.

[9] B. Durakovic and S. Mesetovic, "Thermal performances of glazed energy storage systems with various storage materials: An experimental study," Sustainable Cities and Society, vol. 45, no. Feb, pp. 422-430, 2019.

[10] B. Durakovic and M. Torlak, "Simulation and experimental validation of phase change material and water used as 
heat storage medium in window applications," J. of Mater. and Environ. Sci., vol. 8, no. 5, pp. 1837-1746, 2017.

[11] B. Durakovic, H. Bašić and H. Muhič, "The Interrelationships between quality managment practicies and their effects on innovation," in Trends in the Development of Machinery and Associated Technology, Budapest, 2014.

[12] B. Duraković and H. Bašić, "Textile Cutting Process Optimization Model Based On Six Sigma Methodology In A Medium-Sized Company," Journal of Trends in the Development of Machinery and Associated Technology, vol. 16, no. 1, pp. 107-110, 2012.

[13] H. Bašić, B. Duraković and A. Softić, "Six Sigma Model Testing In Optimizing Medium-Sized Company Production Process," Journal of Trends in the Development of Machinery and Associated Technology, vol. 16, no. 1, pp. 103106, 2012.

[14] B. Durakovic, R. Demir, K. Abat and C. Emek, "Lean Manufacturing: Trends and Implementation Issues," Periodical of Engineering and Natural Sciences, vol. 6, no. 1, pp. 130-143, 2018.

[15] B. Duraković and H. Bašić, "Continuous Quality Improvement in Textile Processing by Statistical Process Control Tools: A Case Study of Medium-Sized Company," Periodicals of Engineering and Natural Sciences, vol. 1, no. 1, pp. 36-46, 2013.

[16] B. Durakovic, "Design of Experiments Application, Concepts, Examples: State of the Art," Periodicals of Engineering and Natural Scinces, vol. 5, no. 3, p. 421-439, 2017.

[17] O. Kerbrat, P. Mognol and J. Y. Hascoët, "A new DFM approach to combine machining and additive manufacturing," Computers in Industry, 2011.

[18] G. Boothroyd, "Product design for manufacture and assembly," Computer-Aided Design, 1994.

[19] T. C. Kuo, S. H. Huang and H. C. Zhang, "Design for manufacture and design for 'X': Concepts, applications, and perspectives," Computers and Industrial Engineering, 2001.

[20] G. D. P. A. K. W. Boothroyd, Product Design for Manufacture and Assembly(2nd edition), New York: Marcel Dekker., 2002.

[21] C. Poli, "Design for Manufacturing: A Structured Approach," Mechanical and Industrial Engineering Department University of Massachusetts Amherst, 2001.

[22] G. Boothroyd, Assembly Automation and Product Design, New York: Taylor and Francis, 2005.

[23] C. Chu, G. Graf and D. W. Rosen, "Design for additive manufacturing of cellular structures," Computer-Aided Design and Applications, 2008.

[24] D. E. Cooper, M. Stanford, K. A. Kibble and G. J. Gibbons, "Additive Manufacturing for product improvement at Red Bull Technology," Materials and Design, 2012.

[25] Y. Huang, M. C. Leu, J. Mazumder and A. Donmez, "Additive Manufacturing: Current State, Future Potential, Gaps and Needs, and Recommendations," Journal of Manufacturing Science and Engineering, 2015.

[26] R. Ponche, O. Kerbrat, P. Mognol and J. Y. Hascoet, "A novel methodology of design for Additive Manufacturing applied to Additive Laser Manufacturing process," Robotics and Computer-Integrated Manufacturing, 2014.

[27] R. Ponche, J. Y. Hascoet, O. Kerbrat and P. Mognol, "A new global approach to design for additive manufacturing," in Additive Manufacturing Handbook: Product Development for the Defense Industry, 2017.

[28] B. Vayre, F. Vignat and F. Villeneuve, "Identification on some design key parameters for additive manufacturing: Application on Electron Beam Melting," in Procedia CIRP, 2013.

[29] N. Hopkinson, R. Hague and P. Dickens, Rapid Manufacturing An Industrial Revolution for the Digital Age, 2006.

[30] E. Atzeni and A. Salmi, "Economics of additive manufacturing for end-usable metal parts," International Journal of Advanced Manufacturing Technology, 2012.

[31] C. C. Seepersad, "Challenges and Opportunities in Design for Additive Manufacturing," 3D Printing and Additive Manufacturing, 2014.

[32] W. C. C. T. Ivanova O, "Additive manufacturing (AM) and nanotechnologypromises and challenges," Rapid Prototyp 
J, vol. 19, no. 5, p. 353-64, 2013.

[33] "Scopus," 2018. [Online]. Available: www.scopus.com. [Accessed May 2018].

[34] M. K. Thompson, G. Moroni, T. Vaneker, G. Fadel, R. I. Campbell, I. Gibson, A. Bernard, J. Schulz, P. Graf, B. Ahuja and F. Martina, "Design for Additive Manufacturing: Trends, opportunities, considerations, and constraints," CIRP Annals - Manufacturing Technology, 2016.

[35] M. P. Caputo, A. E. Berkowitz, A. Armstrong, P. Müllner and C. V. Solomon, "4D printing of net shape parts made from Ni-Mn-Ga magnetic shape-memory alloys," Additive Manufacturing, 2018.

[36] I.Yadroitsev, I.Shishkovsky, P.Bertrand and I.Smurova, "Manufacturing of fine-structured 3D porous filter elements by selective laser melting Author links open overlay panel," Applied Surface Science, vol. 255, no. 10, pp. 55235527, 2009.

[37] D. R. B. S. I. Gibson, Additive manufacturing technologies: 3D printing, rapid prototyping, and direct digital manufacturing, New York: Springer, 2014.

[38] I.Yadroitsev, L. Thivillon, Ph.Bertrand and I.Smurov, "Applied Surface Science Strategy of manufacturing components with designed internal structure by selective laser melting of metallic powder Author links open overlay panel," Applied Surface Science, vol. 254, no. 4, pp. 980-983, 2007.

[39] A. Bandyopadhyay and B. Heer, Additive manufacturing of multi-material structures, 2018.

[40] A. Levy, A. Miriyev, A. Elliott, S. S. Babu and N. Frage, "Additive manufacturing of complex-shaped graded TiC/steel composites," Materials and Design, 2017.

[41] P. Muller, P. Mognol and J. Y. Hascoet, "Modeling and control of a direct laser powder deposition process for Functionally Graded Materials (FGM) parts manufacturing," Journal of Materials Processing Technology, 2013.

[42] J. Chu, S. Engelbrecht, G. Graf and D. W. Rosen, "A comparison of synthesis methods for cellular structures with application to additive manufacturing," Rapid Prototyping Journal, 2010.

[43] B. B., "3-D printing: the new industrial revolution," Bus Horiz, vol. 55, no. 2, pp. 155-62, 2012.

[44] G. A. Adam and D. Zimmer, "Design for Additive Manufacturing-Element transitions and aggregated structures," CIRP Journal of Manufacturing Science and Technology, 2014.

[45] A. du Plessis, P. Sperling, A. Beerlink, W. B. du Preez and S. G. le Roux, "Standard method for microCT-based additive manufacturing quality control 4: Metal powder analysis," MethodsX, vol. 5, pp. 1336-1345, 2018.

[46] Frost \& Sullivan's Global $360^{\circ}$ Research Team, "Global Additive Manufacturing Market, Forecast to 2025," Frost \& Sullivan, 2016.

[47] E. GmbH, "ASS Maschinenbau - Additively Manufactured Robotic Hand for Pharmaceutical Supplier Theo Hillers $\mathrm{GmbH}, "$ [Online]. Available: https://cdn0.scrvt.com/eos/public/f31a95f72c2b78d0/d398604e0e07448cb94721ec3a43496c/download.pdf. [Accessed 21 Oct 2018].

[48] Materialise, "Keeping Intrion Robots Up to Speed," [Online]. Available: https://www.materialise.com/en/cases/keeping-intrion-robots-up-to-speed. [Accessed 24 Oct 2018].

[49] K. Altaf, A. Majdi Abdul Rani and V. R. Raghavan, "Prototype production and experimental analysis for circular and profiled conformal cooling channels in aluminium filled epoxy injection mould tools," Rapid Prototyping Journal, 2013.

[50] E. Sachs, E. Wylonis, S. Allen, M. Cima and H. Guo, "Production of injection molding tooling with conformal cooling channels using the Three Dimensional Printing process," Polymer Engineering and Science, 2000.

[51] E. GmbH, "Plastic Manufacturer FWB Achieves Major Savings in Production Time and Cost Using Additive Manufacturing," [Online]. Available:

https://cdn0.scrvt.com/eos/public/d6021a2d744738ce/d359c096085bce7316bf56d5c9341a4d/fwb.pdf. [Accessed 15 Dec 2018].

[52] G. I. Rozvany, "A critical review of established methods of structural topology optimization," Structural and 
Multidisciplinary Optimization, 2009.

[53] M. Tomlin and J. Meyer, "Topology optimization of an Additive Layer Manufactured (ALM) aerospace part," in 7th Altair CAE Technology, 2011.

[54] O. Cansizoglu, O. L. Harrysson, H. A. West, D. R. Cormier and T. Mahale, "Applications of structural optimization in direct metal fabrication," Rapid Prototyping Journal, 2008.

[55] "EADS and EOS - Study Demonstrates Savings Potential for DMLS in the Aerospace Industry," 2018. [Online]. Available: https://cdn0.scrvt.com/eos/public/3fb75eeabb786ba7/6bea4ef6e33191ffaf0372fd47e8601a/download.pdf. [Accessed 21 Oct 2018].

[56] B. Vayre, F. Vignat and F. Villeneuve, "Designing for additive manufacturing," in Procedia CIRP, 2012.

[57] G. A. Bingham, R. J. Hague, C. J. Tuck, A. C. Long, J. J. Crookston and M. N. Sherburn, "Rapid manufactured textiles," International Journal of Computer Integrated Manufacturing, 2007.

[58] A. Johnson, G. A. Bingham and D. I. Wimpenny, "Additive manufactured textiles for high-performance stab resistant applications," Rapid Prototyping Journal, 2013.

[59] Y. Chen and C. Zhezheng, "Joint analysis in rapid fabrication of non-assembly mechanisms," Rapid Prototyping Journal, 2011.

[60] F. Calignano, D. Manfredi, E. P. Ambrosio, S. Biamino, M. Pavese and P. Fino, "Direct fabrication of joints based on direct metal laser sintering in aluminum and titanium alloys," in Procedia CIRP, 2014.

[61] "Aalto University Digital Design Laboratory, Nanoshell: Unity," [Online]. Available: http://addlab.aalto.fi/designresearch/projects/nanoshell. [Accessed 21 Oct 2018].

[62] R. Stott, "Synthesis Design + Architecture Utilizes Gradient 3-D Printing in Durotaxis Chair. ArchDaily," [Online]. Available: https://www.archdaily.com/610939/synthesis-design-architecture-utilizes-gradient-3-d-printing-indurotaxis-chair. [Accessed 21 Oct 2018].

[63] "Stratasys, Multi-Material 3D Printing," [Online]. Available: https://www.stratasys.com/polyjet-technology. [Accessed 21 Oct 2018].

[64] M. Vaezi, S. Chianrabutra, B. Mellor and S. Yang, "Multiple material additive manufacturing - Part 1: a review," Virtual and Physical Prototyping, 2013.

[65] N. Oxman, "Variable property rapid prototyping," Virtual and Physical Prototyping, 2011.

[66] A. T. Gaynor, N. A. Meisel, C. B. Williams and J. K. Guest, "Multiple-Material Topology Optimization of Compliant Mechanisms Created Via PolyJet Three-Dimensional Printing," Journal of Manufacturing Science and Engineering, 2014.

[67] M. Y. Wang and X. Wang, "'Color" level sets: A multi-phase method for structural topology optimization with multiple materials," Computer Methods in Applied Mechanics and Engineering, 2004.

[68] J. Corney, R. Becker, A. Grzesiak and A. Henning, Rethink assembly design, 2005.

[69] R. A. Buswell, R. C. Soar, A. G. F. Gibb and A. Thorpe, "Freeform Construction: Mega-scale Rapid Manufacturing for construction," Automation in Construction, 2007.

[70] "FDM Helps Acist Medical Pursue perfection," [Online]. Available: http://usglobalimages.stratasys.com/Case\%20Studies/Medical/CS-FDM-Med-AcistMedical-EN-03-15Web.pdf?v=635708250049307509. [Accessed 20 2018dEC].

[71] E. Lutters, F. J. Van Houten, A. Bernard, E. Mermoz and C. S. Schutte, "Tools and techniques for product design," CIRP Annals - Manufacturing Technology, 2014.

[72] J. Hascoët, R. Ponche, O. Kerbrat and P. Mognol, "From functional specifications to optimized CAD model : proposition of a new DFAM methodology," in Proceedings of the ASME Design Engineering Technical Conferences and Computers and Information in Engineering Conference, 2011.

[73] Y. Zhang, A. Bernard, R. K. Gupta and R. Harik, "Evaluating the design for additive manufacturing: A process 
planning perspective," in Procedia CIRP, 2014.

[74] P. O'Regan, P. Prickett, R. Setchi, G. Hankins and N. Jones, "Metal Based Additive Layer Manufacturing: Variations, Correlations and Process Control," Procedia Computer Science, vol. 96, pp. 216-224, 2016.

[75] L. G, S. P and S. A. B, "Total Quality Management (TQM) Model for Rapid Manufacturing.," in Rapid Manufacturing Conference, Loughborough, 2006.

[76] M. Schmid and G. Levy, "Quality Management and Estimation of Quality Costs for Additive Manufacturing with SLS," in Direct Digital Manufacturing Conference (Ed.), Direct Digital Manufacturing Conference, 2012.

[77] M. Schmidt, M. Merklein, D. Bourell, D. Dimitrov, T. Hausotte, K. Wegener, L. Overmeyer, F. Vollertsen and G. N. Levy, "Laser based additive manufacturing in industry and academia," CIRP Annals, 2017.

[78] P. O'Regan, P. Prickett, R. Setchi, G. Hankins and N. Jones, "Metal Based Additive Layer Manufacturing: Variations, Correlations and Process Control," Procedia Computer Science, vol. 96, pp. 216-224, 2016.

[79] O. Rehme and C. Emmelmann, "Reproducibility for Properties of Selective Laser Melting Products," in INTERNATIONAL CONFERENCE; 3rd, Lasers in manufacturing; LIM 2005, Munich, 2005. 